\title{
Promoting Difficult C-C Couplings: Which Ligand Does Best?
}

\author{
Estefanía Gioria, Juan delPozo, Jesús M. Martínez-llarduya, and Pablo Espinet *[a] \\ Dedicated to Prof. Juan O. Forniés in recognition to his long standing valuable contribution to Pd chemistry with fluoroaryl ligands
}

\begin{abstract}
A Pd complex, cis- $\left[\mathrm{Pd}\left(\mathrm{C}_{6} \mathrm{~F}_{5}\right)_{2}(\mathrm{THF})_{2}\right]$, is proposed as a useful touchstone for direct and simple experimental measurement of the relative ability of ancillary ligands to induce $\mathrm{C}-\mathrm{C}$ coupling. The procedure ranks this ability for some popular ligands in the order $\mathrm{P}^{\mathrm{t}} \mathrm{Bu}_{3}>$ o-TolPEWO-F $\approx \mathrm{tBuXPhos}>\mathrm{P}\left(\mathrm{C}_{6} \mathrm{~F}_{5}\right)_{3} \approx \mathrm{PhPEWO}-\mathrm{F}>\mathrm{P}(0-$ $\mathrm{Tol})_{3} \approx \mathrm{THF} \approx \mathrm{tBuBrettPhos}>>$ Xantphos $\approx \mathrm{PhPEWO}-\mathrm{H}>>\mathrm{PPh}_{3}$ according to their coupling initial rates, whereas their efficiency, depending on competitive hydrolysis, is ranked tBuXPhos $\approx \mathrm{PtBu}_{3} \approx$ o-TolPEWO-F > PhPEWO-F $>\mathrm{P}\left(\mathrm{C}_{6} \mathrm{~F}_{5}\right)_{3}>$ tBuBrettPhos $>$ THF $\approx$ $\mathrm{P}(\mathrm{o}-\mathrm{Tol})_{3}>$ Xantphos > PhPEWO-H >> $\mathrm{PPh}_{3}$. This "meter" also detects some other possible virtues or complications of ligands such as $\mathrm{tBuXPhos}$ or tBuBrettPhos.
\end{abstract}

$\mathrm{Pd}$ catalyzed cross-coupling reactions involve several steps, but reductive elimination is most decisive because it is typically irreversible, which is the driving force pulling forward the whole catalytic cycle. ${ }^{1}$ When the reductive elimination is slow competitive side-reactions from the $\left[P d R^{1} R^{2} L_{2}\right]$ intermediates formed in the course of the catalytic cycle, such as homocoupling, $\beta$-hydride elimination, hydrolysis, or others, can dramatically decrease the yield of the desired $R^{1}-R^{2}$ product. Examples of challenging reductive eliminations are those forming $\mathrm{Ar}-\mathrm{N}^{[2]} \mathrm{Ar}-\mathrm{O},{ }^{[3]}$ or $\mathrm{Ar}-\mathrm{F}$ bonds. ${ }^{[4]}$ The often facile $\mathrm{C}-\mathrm{C}$ couplings are also difficult when they involve perfluoroaryls, ${ }^{[5]}$ or perfluoroalkyls $\left(\text { e.g. } \mathrm{CF}_{3}\right)^{[6,3 c]}$.

Along the oxidation step, two electrons of the $\mathrm{Pd}^{0}$ atom get involved in the formation of two $P d^{\prime \prime}-R$ bonds (Equation 1), which is favored for electron-rich Pd centres. In the opposite sense, along the reduction process the $\mathrm{Pd}^{0}$ center gains electron density. It immediately follows that (for the same $R^{1}$ and $R^{2}$ groups involved) ancillary ligands able to withdraw electron density from $\mathrm{Pd}$ should favor the reductive elimination by lowering the corresponding activation barrier.

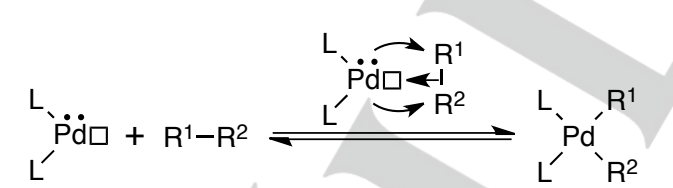

The collection of ligands in Chart 1 , available to us to check their relative ability to induce reductive elimination, model the following classes: i) weak ligands facilitating ligand dissociation to short-living tricoordinated $\mathrm{Pd}^{\prime \prime}$ intermediates (THF, $\left.\mathrm{P}\left(\mathrm{C}_{6} \mathrm{~F}_{5}\right)_{3}\right)$; ii) bulky ligands providinging low energy access to tricoordinated complexes $\left(\mathrm{P}^{\mathrm{t}} \mathrm{Bu}_{3}, \mathrm{P}(\mathrm{o}-\mathrm{Tol})_{3}\right.$, tBuXPhos, tBuBrettPhos and the

[a] Ms. Gioria, E.; Dr. delPozo, J.; Dr. Martínez-Ilarduya, J. M.; Prof. Dr. Espinet, $P$ **

IU CINQUIMA/Química Inorgánica, Facultad de Ciencias,

Universidad de Valladolid, Paseo de Belén, 9, ES47071.

E-mail: espinet@qi.uva.es

Supporting information for this article is given via a link at the end of the document.((Please delete this text if not appropriate)) previously unreported o-ToIPEWO-F); iii) ligands with electronwithdrawing potential (PhPEWO-F, o-TolPEWO-F, PhPEWO-H, $\mathrm{P}\left(\mathrm{C}_{6} \mathrm{~F}_{5}\right)_{3}$, tBuXPhos and tBuBrettPhos); and iv) large bite-angle ligands (e.g. Xantphos).

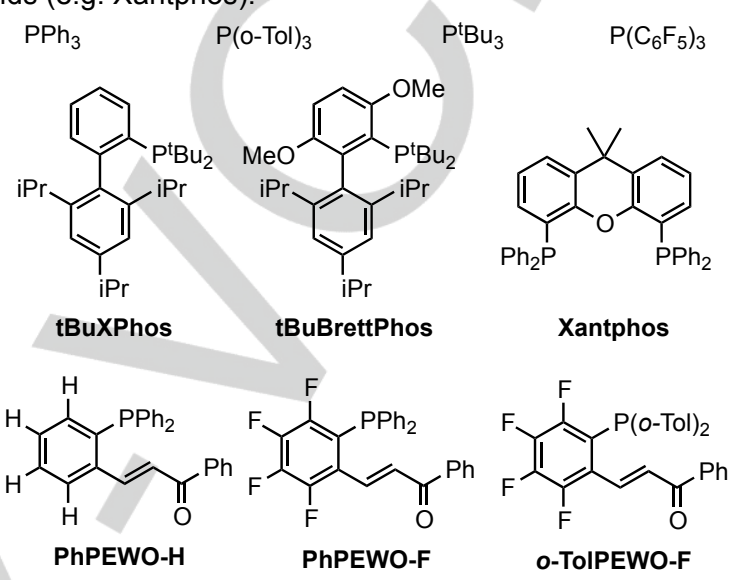

Chart 1. Phosphine ligands used in this work.

A ranking of the relative ability of ligands to induce reductive elimination should be of help for a more rational ligand choice in catalysis but it is difficult to measure this ability in the context of an active catalysis. Here we propose the use as "meter" of cis$\left[\mathrm{PdPf}_{2}(\mathrm{THF})_{2}\right]\left(\mathrm{Pf}=\mathrm{C}_{6} \mathrm{~F}_{5}\right)(\mathbf{1}){ }^{7}$ on which the rates and activation energies for the process in Equation 2 can be measured directly for different ligands.

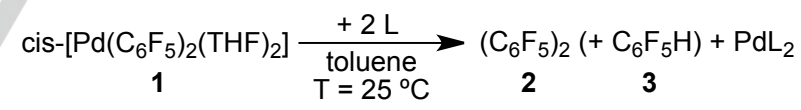

Complex 1 is convenient for a number of reasons: $i)$ the two Pf groups to be coupled are already in a cis arrangement sparing the kinetic interference of an isomerization process; ii) THF is a very weak ligand for $\mathrm{Pd}$, which is displaced fast by even fairly weak ligands, ${ }^{8}$ so THF substitution by ligand in Chart 1 can be considered instantaneous compared to reductive elimination. These two conditions are major requirements for a valid coupling rate determination; we tried $\left[\mathrm{PdPf}_{2}(\mathrm{COD})\right]$ and found that the coupling rate is often determined by the COD displacement step and not by the coupling step itself, making impossible to measure coupling activation energies. iii) complex $\mathbf{1}$ is conveniently easy to make, handle and store; iv) the coupling reaction is easily monitored by ${ }^{19} \mathrm{~F}$ NMR in protic toluene, where the $F_{o}$ and $F_{p}$ signals of 1 and 2 (also 3 ) can be precisely integrated; and $v$ ) the Pf-Pf coupling rate is slow compared to conventional aryls, which facilitates kinetic studies for efficient ligands at room or not very low temperature. The reductive elimination from 1, either spontaneous (for complex 1) or induced by addition of the ligands in Chart 1 , was studied monitoring the rate of formation of decafluorobiphenyl (Pf-Pf, 2). In several cases $\mathrm{C}_{6} \mathrm{~F}_{5} \mathrm{H}$ (3) was also detected (Equation 2). It is formed by slow Pd-Pf hydrolysis by adventitious water in the dry 
toluene solvent, ${ }^{[9]}$ This was confirmed using toluene saturated with $\mathrm{D}_{2} \mathrm{O}$ for the reaction in entry 7 , which afforded a mixture of $\mathrm{C}_{6} \mathrm{~F}_{5} \mathrm{H}$ and $\mathrm{C}_{6} \mathrm{~F}_{5} \mathrm{D}$ (see $\mathrm{SI}$ for details).

Adding $\mathrm{PPh}_{3}$, a most frequent ligand for $\mathrm{Pd}$, produced immediately cis-[PdPf$\left.{ }_{2}\left(\mathrm{PPh}_{3}\right)_{2}\right]{ }^{[10]}$ which was indefinitely stable in solution indicating too high coupling activation energy for measuring it at room temperature. ${ }^{[11]}$ For the rest of the ligands the results are shown in Table 1 , where $\Delta G^{\ddagger}(P f-P f)$ values, as measured from initial reaction rates, are given. The effect of the comparatively slow competitive formation of $\mathrm{C}_{6} \mathrm{~F}_{5} \mathrm{H}$ on the measurement of $\Delta \mathrm{G}^{\ddagger}(\mathrm{Pf}-\mathrm{Pf})$ values is small (except perhaps for entry 7 ) because it hardly affects the initial concentrations. The spontaneous coupling and hydrolysis of cis-[PdPf $\left.2(\mathrm{THF})_{2}\right]$ (1), just discussed, serves as reference for the different ligands.

Table 1. Experimental activation barriers $\Delta G^{\ddagger}(\mathrm{Pf}-\mathrm{Pf})$ for the reductive elimination of cis-[ $\left.\mathrm{PdPf}_{2}(\mathrm{THF})_{2}\right]$ promoted by different ligands in Chart 1 , at $\mathrm{T}=25^{\circ} \mathrm{C}$ (except for entries $1-3$, at $\mathrm{T}=0{ }^{\circ} \mathrm{C}$ ), and products obtained.

\begin{tabular}{|c|c|c|c|c|}
\hline Entry & Ligand & $\begin{array}{l}\Delta \mathrm{G}^{\ddagger}(\mathrm{Pf}-\mathrm{Pf}) \\
\left(\mathrm{kcal}^{-\mathrm{mol}^{-1}}\right)\end{array}$ & $\begin{array}{l}\text { Products }^{[c]} \\
\text { Pf-Pf\%:Pf- } \\
\mathrm{H} \%\end{array}$ & Time $(h)^{[d]}$ \\
\hline 1 & $\mathrm{P}^{t} \mathrm{Bu}_{3}$ & $20.7^{[\mathrm{a}]}$ & $98.0: 2.0$ & 4 \\
\hline 2 & o-TolPEWO-F & $21.6^{[a]}$ & $97.7: 2.3$ & 1.4 \\
\hline 3 & tBuXphos & $21.8^{[\mathrm{a}][\mathrm{b}]}$ & $100: 0$ & 2.6 \\
\hline 4 & $\mathrm{P}\left(\mathrm{C}_{6} \mathrm{~F}_{5}\right)_{3}$ & 22.2 & $95.5: 4.5$ & 8 \\
\hline 5 & PhPEWO-F & 22.5 & $93.7: 6.3$ & 5.6 \\
\hline 6 & $\mathrm{P}(\mathrm{o}-\mathrm{Tol})_{3}$ & 23.0 & $41.6: 2.1$ & 6 \\
\hline 7 & THF & 23.1 & $48.0: 7.2$ & 8 \\
\hline 8 & tBuBrettphos & $23.3^{[\mathrm{b}]}$ & $49.0: 0$ & 8 \\
\hline 9 & Xantphos & 24.2 & $19.1: 0$ & 8 \\
\hline 10 & PhPEWO-H & 24.6 & $15.3: 0.8$ & 8 \\
\hline
\end{tabular}

[a] Measurement of initial rates was performed at $\mathrm{T}=0{ }^{\circ} \mathrm{C}$ for higher precision. [b] 3 eq. of $p-\mathrm{FC}_{6} \mathrm{H}_{4} \mathrm{I}$ were added. [c] In toluene, at $\mathrm{T}=25^{\circ} \mathrm{C}$ Yields obtained by ${ }^{19} \mathrm{~F}$ NMR integration using $\mathrm{PhCF}_{3}$ as internal standard. [d] After $8 \mathrm{~h}$ or times indicated when the reaction is practically finished.

All the curves of formation of $\mathbf{2}$ are regular except for tBuXphos where $\mathbf{2}$ is first formed and then consumed during the process because the para $\mathrm{C}-\mathrm{F}$ bonds of 2 oxidatively add to the $\mathrm{Pd}^{0}$ (tBuXphos) formed (Figure 1; see $\mathrm{SI}$ for details). This complicates the measurement of coupling rate. Addition of $p-\mathrm{FC}_{6} \mathrm{H}_{4}$ l prevents this effect by quickly oxidizing $\mathrm{Pd}^{0}$ (tBuXphos) to non-interfering [Pd"(tBuXphos) $\left(\mathrm{C}_{6} \mathrm{H}_{4} \mathrm{~F}\right) \mathrm{l}$, thus this additive was incorporated as a general precaution.

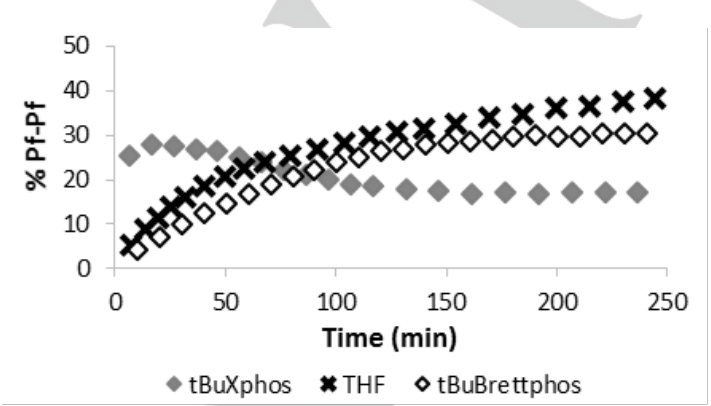

Figure 1. Percentages of Pf-Pf not adding Arl by promoted by ligands in Chart 1. The line with THF is kept as in Figure 2 for reference.
The evolution of formation of $\mathbf{2}$ upon addition of each of the ligands, in the conditions specified in Table 1, is regular for all of them (Figure 2). From these experiments the ligand's coupling ability I quantitatively ranked by their $\Delta G^{\ddagger}$ values: $\mathrm{P}^{\mathrm{t}} \mathrm{Bu}_{3}>$ o-TolPEWO-F $\approx \mathrm{tBuXPhos}>\mathrm{P}\left(\mathrm{C}_{6} \mathrm{~F}_{5}\right)_{3} \approx \mathrm{PhPEWO}-\mathrm{F}$ $>\mathrm{P}(\mathrm{o}-\mathrm{Tol})_{3} \approx \mathrm{THF} \approx \mathrm{tBuBrettPhos}>>$ Xantphos $\approx \mathrm{PhPEWO}$ $\mathrm{H}>\mathrm{PPh}_{3}{ }^{12}$

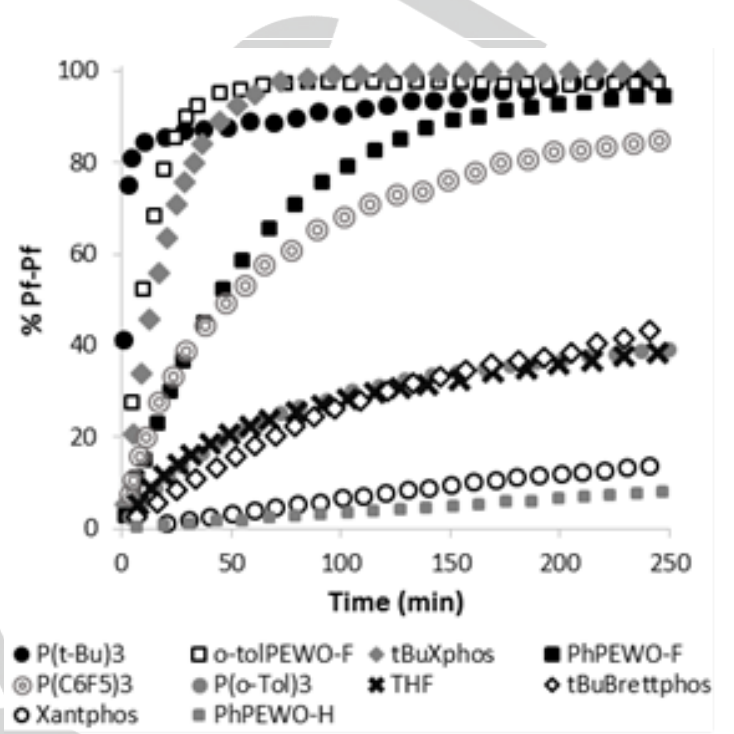

Figure 2. Percentages of $\mathrm{Pf}$ (relative to the starting material 1) obtained as Pf-Pf promoted by ligands in Chart 1 . All at $25^{\circ} \mathrm{C}$, in toluene. $\mathrm{L}: 1=2: 1$.

In addition to ranking their coupling ability, the results of eq. (2) uncover other interesting aspects of the behavior of the ligands. These are discussed with the help of Scheme 1, which summarizes the pathways observed to operate in the reactions $1+2 \mathrm{~L}$ used to build Table 1 .

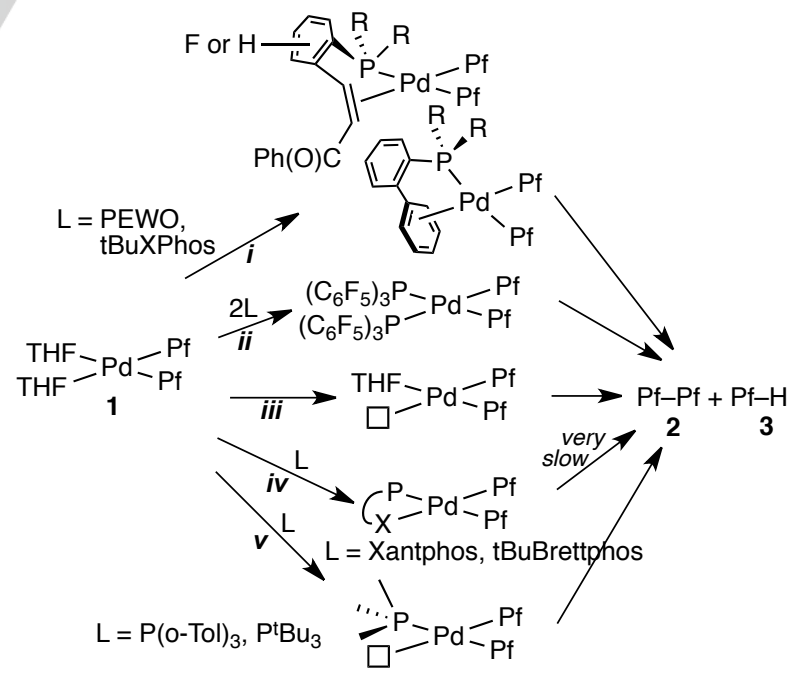

Scheme 1. Reaction products formed by reaction of 1 with different ligands.

First of all, the meter complex cis-[PdPf $\left.\mathrm{PdHF}_{2}\right]$ (1), which can be easily prepared and handled in THF, decomposes 
slowly but spontaneously when dissolved in noncoordinating solvents: THF is poorly coordinated to Pd", and dissociates easily in the absence of external THF, probably facilitating coupling from a tricoordinated cis-[PdPf $\left.\mathrm{PdHF}_{2}(\mathrm{TH})\right]$ (Scheme 1, path iii) ${ }^{[1]}$ Concomitant hydrolysis from adventitious cis-[ $\left[\mathrm{PdPf}_{2}(\mathrm{THF})\left(\mathrm{OH}_{2}\right)\right]$ molecules compete with $\mathrm{Pf}-\mathrm{Pf}$ coupling, more favorably in this case than in any of the others according to Table 1 . Since the reductive elimination has a moderate rate and the presence of molecules with coordinated water (more acidic) is more abundant than in the other entries of Table 1, spontaneous decomposition of 1 affords the highest PfH proportion (Pf-Pf:Pf-H = 48:7.2).

For Xantphos coupling is one of the slowest, but no $\mathrm{PfH}$ is detected. The immediately formed cis-[PdPf $($ Xantphos $)]$ (Scheme 1, path $i v$ ), which gives reductive elimination only very slowly, also prevents thermodynamically coordination of any $\mathrm{OH}_{2}$, thus blocking formation of $\mathrm{PfH}$. Although the facilitation of reductive elimination processes by Xantphos at $80{ }^{\circ} \mathrm{C}$ is well established ${ }^{[6 a, b]}$ this ligand cannot deal with the Pf-Pf coupling at room temperature, showing that our coupling-meter complex is a very demanding for the ligands. ${ }^{[13]}$

Very interestingly, the two phosphines $\mathrm{P}^{\mathrm{t}} \mathrm{Bu}_{3}$ and $\mathrm{P}\left(\mathrm{C}_{6} \mathrm{~F}_{5}\right)_{3}$ are quite efficient for coupling (Scheme 1, paths $\boldsymbol{v}$ and $\boldsymbol{i}$ ), in spite of being electronically very different, although slower coupling and higher percentage of $\mathrm{PfH}$ is observed for the latter. They represent the two possible and apparently contradictory models that favor coupling by reducing the activation energy: a) bulky and strongly $\sigma$ donor ligands that force functionally tricoordinated complexes by rising the ground state energy of the starting complex as compared to four coordination; ${ }^{[14]}$ and b) poorly $\sigma$-donor but strongly $\pi$-acceptor ligands that stabilize the TS by minimizing electronic repulsions in the evolution towards $\mathrm{Pd}^{0}{ }^{[1]}$ In contrast to the good donor $\mathrm{P}^{t} \mathrm{Bu}_{3}, \mathrm{P}\left(\mathrm{C}_{6} \mathrm{~F}_{5}\right)_{3}$ is a poor $\sigma$ donor ligand (hence a weak ligand for $\mathrm{Pd}^{\prime \prime}$, although strong $\pi^{*}$ acceptor from $\mathrm{Pd}^{0}$ at the $\sigma^{*} \mathrm{P}-\mathrm{C}$ orbitals), so that cis$\left[\mathrm{PdPf}_{2}\left(\mathrm{PR}_{3}\right)_{2}\right]\left(\mathrm{R}=\mathrm{C}_{6} \mathrm{~F}_{5}\right)$ easily dissociates phosphine. Assuming that $\mathrm{PhH}$ is formed in both cases from cis-[ $\left[\mathrm{PdPf}_{2}\left(\mathrm{PR}_{3}\right)\left(\mathrm{OH}_{2}\right)\right]$ complexes (entries 1 and 4), the acidity of the coordinated $\mathrm{OH}_{2}$ in the complex, as well as the percentage of these molecules in solution, should be higher and more efficient towards hydrolysis for $\mathrm{P}\left(\mathrm{C}_{6} \mathrm{~F}_{5}\right)_{3} . \mathrm{P}(\mathrm{o}-\mathrm{Tol})_{3}($ Scheme 1, path $\boldsymbol{v})$, less donor and less bulky than $\mathrm{P}^{\mathrm{t}} \mathrm{Bu}_{3}$, and also much less acceptor than $\mathrm{P}\left(\mathrm{C}_{6} \mathrm{~F}_{5}\right)_{3}$, affords slower coupling rate than the other two, and more hydrolysis than $\mathrm{P}^{\mathrm{t}} \mathrm{Bu}_{3}$.

Overall the formation of $\mathrm{PfH}$ is clearly more efficient in complexes with a strongly withdrawing olefin (o-TolPEWO-F, $2.3 \% \mathrm{PfH}$ in $1.4 \mathrm{~h}$; PhPEWO-F $6.3 \% \mathrm{PfH}$ in $5.6 \mathrm{~h}$; Table 1, entries 2 and 5), than in PhPEWO-H with a less $\pi$ - acceptor olefin fragment (entry $10,0.8 \% \mathrm{PfH}$ in $8 \mathrm{~h}$ ). However, this inconvenience is compensated by their higher coupling rates, which lead to better Pf-Pf/PfH ratios in the order o-TolPEWO-F > PhPEWO-F > PhPEWO-H. Interestingly PhPEWO-F and PhPEWO-H have practically identical size and their remarkably different behavior highlights the enormous effect of the fluorinated aryl ring on the $\pi$-acceptor effect of the PEWO2 and PEWO1 olefinic fragment. On the other hand, PEWO1 and
PEWO2 (Scheme 1, path $\boldsymbol{i}$ ) share an identical m-acceptor moiety but have $\mathrm{PR}_{2}$ fragments of very different size. Consistently, the one with larger substituents (PEWO2) shows a remarkably faster coupling rate.

Quite unexpectedly, considering its structural similarity with tBuXphos, tBuBrettphos proved to be inefficient for coupling. At variance with tBuXphos, the course of formation of $\mathbf{2}$ with tBuBrettphos in Figure 1 is quite regular but slow, and using $p$ $\mathrm{FCH}_{4} \mathrm{l}$ the profile changes only slightly at later stages of the reaction (Figure 2). This points clearly to a different cause of the problem, which can be traced to the existence of two possible bond isomers for tBuBrettphos: $P, O$-bound and $P, C$-bound (Scheme 2). In fact a very similar $P, O$-bound complex was found by $\mathrm{X}$-ray diffraction for $\left[\mathrm{Pd}\left(\mathrm{C}_{6} \mathrm{H}_{4}-\mathrm{CO}_{2} \mathrm{Me}-p\right)\left(\mathrm{CF}_{3}\right)(\right.$ CyBrettphos $\left.)\right]$, having (by DFT calculations) an activation energy towards reductive elimination of $\mathrm{F}_{3} \mathrm{C}-\mathrm{C}_{6} \mathrm{H}_{4} \mathrm{CO}_{2} \mathrm{Me}-p$ about $5 \mathrm{kcal} \mathrm{mol}^{-1}$ higher than its non observed by NMR $P, C$-bound isomer. ${ }^{[6 \mathrm{~d}]}$

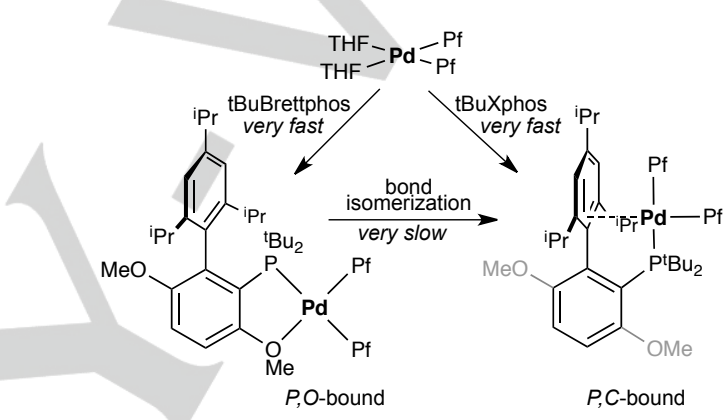

Scheme 2. Different coordination behavior of tBuXphos and tBuBrettphos.

The ${ }^{19} \mathrm{~F}$ NMR spectra of the Pd complex formed in our case is intrinsically very complex, providing less precise structural information, but the kinetic behavior observed strongly suggests that: i) the isomer formed with tBuBrettphos in Scheme 2 is the $P, O$-bound isomer, from which reductive elimination is occurring slowly; ii) $P, O$-bound to $P, C$-bound isomerization does not occur after long time at room temperature or it would provoke a sharp increase in coupling rate that is not observed; iii) the $\mathrm{Pd}^{0}$ (tBuBrettphos) complex formed upon reduction at room temperature probably remains $P, O$-bound since, in contrast with $\mathrm{Pd}^{0}$ (tBuXphos), it is not able to activate $\mathrm{C}-\mathrm{F}$ oxidation of the decafluorobiphenyl; iv) $P, O$-bound to $P, C$-bound isomerization occurs only upon oxidation with $p-\mathrm{IC}_{6} \mathrm{H}_{4} \mathrm{~F}$, as supported by the cation X-ray structure of $\left[\mathrm{Pd}\left(\mathrm{C}_{6} \mathrm{H}_{4} \mathrm{CF}_{3}\right)(\text { tBuBrettphos })\right]_{2}[(\mu-$ $\left.\mathrm{I}_{2}\left(\mathrm{PdPf}_{2}\right)_{2}\right]$ (Chart 2 and $\mathrm{SI}$ ), which was crystallized from the mother liquors of the reaction in entry 8 of Figure 1.

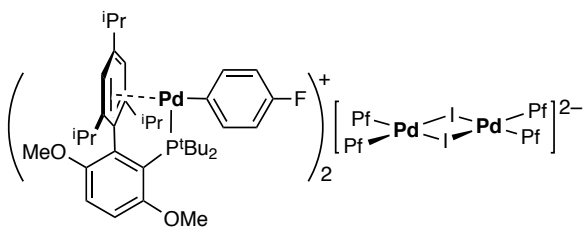

Chart 2. Cation and anion structures of the ionic complex $\left[\mathrm{Pd}\left(\mathrm{C}_{6} \mathrm{H}_{4} \mathrm{~F}\right) \text { (tBuBrettphos) }\right]_{2}\left[(\mu-\mathrm{I})_{2}\left(\mathrm{PdPf}_{2}\right)_{2}\right]$ found by $\mathrm{X}$-ray diffraction (see $\mathrm{SI}$ ). 
Concerning the absence of $\mathrm{PfH}$ in reactions with the ligands tBuXphos and tBuBrettphos, this result suggests that the former prevents coordination of water to the $P, C$-bound species more efficiently that any of the other ligands helped by steric hindrance, while the later, acting as $P, O$ chelate, does not offer an available coordination position to water (a case similar to the $P, P$-chelate Xantphos)

Overall, particularly considering the undesired competing hydrolisis, the efficiency for coupling may be ranked tBuXPhos $\approx$ $\mathrm{PtBu}_{3} \approx$ o-TolPEWO-F $>$ PhPEWO-F $>\mathrm{P}\left(\mathrm{C}_{6} \mathrm{~F}_{5}\right)_{3} \gg$ tBuBrettPhos $>$ THF $\approx \mathrm{P}(\mathrm{o}-\mathrm{Tol})_{3}>$ Xantphos $>$ PhPEWO-H $>>$ $\mathrm{PPh}_{3}$. Obviously this preference should not be generalized to the whole catalytic cycle because other steps can be rate determining or fail; to mention just an obvious case, THF would not keep the catalyst alive through the $\mathrm{Pd}^{0}$ stage.

In conclusion, complex cis-[PdPf$\left.f_{2}(\mathrm{THF})_{2}\right]$ (1) is a convenient touchstone that only requires the time of monitoring the formation of the coupling product Pf-Pf (2) to have quick information on old or newly synthesized ligands. Our protocol is useful to measure and rank experimentally the ability of ligands to promote electronically difficult couplings, isolated from other processes or steps. Moreover, the hydrolysis product $\mathbf{3}$ informs of the rate of this competitive unwanted process. In addition, our system happens to detect some side reactions with useful meaning: The consumption of $\mathbf{2}$ in the case of $\mathrm{tBuXPhos}$ reports on the extremely good performance of this ligand in the oxidative addition step; the initially deceptive data of tBuBrettPhos might suggest to use it on $\mathrm{Pd}^{0}$ and not on a Pd" catalyst precursor to try to get a more active $P, C$-isomer from the beginning.

The scale of relative $\Delta \mathrm{G}^{\ddagger}(\mathrm{Pf}-\mathrm{Pf})$ values, to which other ligands may be incorporated in the future, can help for a more precise understanding of the phenomena associated to difficult couplings. It is not unreasonable that the ligand trend observed with this meter could approximately apply to other difficult couplings, or to easier homo- or hetero-couplings not measurable because they are too fast.

The new ligands o-ToIPEWO-F and PhPEWO-F, which do not suffer easy oxidation, are much more efficient than $\mathrm{PhPEWO}-\mathrm{H}$, and the former is as fast for the coupling step as the excellent $\mathrm{tBuXPhos}$ or the pyrophoric $\mathrm{P}^{\mathrm{t}} \mathrm{Bu}_{3}$. However, it is tBuXPhos the one that combines best a highly efficient coupling performance with an extraordinary capability to give oxidative addition with difficult ArX electrophiles. Other members of the PEWO family are being developed.

\section{Experimental Section}

Experimental Details are given in the supplementary information (please add link)

\section{Acknowledgements}

This research was sponsored by the Spanish MINECO (grants CTQ2013-48406-P and CTQ2014-52796-P), and by the Junta de Castilla y León (grant VA256U13). E. G and J.dP thank FPU grants of the Spanish MECD.

Keywords: cross-coupling $\cdot$ reductive elimination $\cdot$ mechanisms - bulky phosphines $\cdot$ palladium catalysis

[1] M. Pérez-Rodríguez, A. A. C. Braga, M. García-Melchor, M. H. PérezTemprano, J. A. Casares, G. Ujaque, A. R. de Lera, R. Álvarez, F. Maseras, P. Espinet, J. Am. Chem. Soc. 2009, 131, 3650-3657.

[2] a) D. S. Surry, S. L. Buchwald, Chem. Sci. 2011, 2, 27. b) J. L. Klinkenberg, J. F. Hartwig, J. Am. Chem. Soc., 2010, 132, 1183011833.

[3] a) C. W. Cheung, S. L. Buchwald, J. Org. Chem. 2014, 79, 5351-5358. b) T. Schulz, C. Torborg, B. Schäffner, J. Huang, A. Zapf, R. Kadyrov, A. Börner, M. Beller, Angew. Chem. Int. Ed. 2009, 48, 918-921; Angew. Chem. 2009, 121, 936-939. c) J. P. Stambuli, Z. Weng, C. D. Incarvito, J. F. Hartwig, Angew. Chem. Int. Ed. 2007, 46, 7674-7677; Angew. Chem. 2007, 119, 7818-7821.

[4] a) H. G. Lee, P. J. Milner, S. L. Buchwald, J. Am. Chem. Soc. 2014 136, 3792-3795. b) H. G. Lee, P. J. Milner, S. L. Buchwald, Org. Lett. 2013, 15, 5602-5605. c) D. A. Watson, M. Su, G.; Teverovskiy, Y Zhang, J. García-Fortanet, T. Kinzel, S. L. Buchwald, Science 2009, 325, 1661-1664.

[5] a) A. C. Albéniz, J. A. Casares, Adv. Organomet. Chem. 2014, 62, 1110. b) M. Ohashi, R. Doi, S. Ogoshi, Chem. Eur. J. 2014, 20, 20402048. c) N. C. Bruno, N. Niljianskul, S. L. Buchwald, J. Org. Chem. 2014, 79, 4161-4166. d) H. Zhang, J. Dong, Q. Hu, Eur. J. Org. Chem 2014, 1327-1332. e) M. Majchrzak, S. Kostera, M. Kubicki, I. Kownacki, Dalton Trans., 2013, 42, 15535-15539. f) M. Lafrance, D. Shore, K. Fagnou, Org. Lett. 2006, 8, 5097-5100.

[6] a) V. V. Grushin, W. J. Marshall, J. Am. Chem. Soc.; 2006, 128, $12644-$ 12645. b) V. V Grushin, W. J. Marshall, Organometallics 2007, 26, 4997-5002. c) E. J. Cho, T. D. Senecal, T. Kinzel, Y. Zhang, D. A. Watson, S. L. Buchwald, Science 2010, 328, 1679-1681. d) M. C. Nielsen, K. J. Bonney, F. Schoenebeck, Angew. Chem. Int. Ed. 2014, 53, 5903-5906; Angew. Chem. 2014, 126, 6013-6016.

[7] R. Usón, J. Forniés, M. Tomás and B. Menjón, Organometallics, 1985, 4, 1912-1914.

[8] R. Usón, J. Forniés, M. Tomás, B. Menjón, R. Navarro, J. Carnicer Inorg. Chim. Acta 1989, 162, 33-37.

[9] $6 \mathrm{ppm}$ by Karl Fischer determination (more details in SI)

[10] a) R. Usón, J. Forniés, P. Espinet, F. Martínez, M. Tomás, J. Chem. Soc., Dalton Trans., 1981, 463-465. b) G. B. Deacon, I. L. F. Grayson Transition Met. Chem. 1983, 8, 131-139.

[11] cis-[PdRf $\left.\left(\mathrm{PPh}_{3}\right)_{2}\right]$ gives rise to a cis/trans equilibrium but does not produce reductive elimination at room temperature.

[12] Note that $\Delta \mathrm{G}^{\ddagger}(\mathrm{Pf}-\mathrm{Pf})$ for the first three ligands in the list was determined at $0{ }^{\circ} \mathrm{C}$ and for the others at $25^{\circ} \mathrm{C}$.

[13] The $\mathrm{C}_{6} \mathrm{~F}_{5}$ group is quite electronegative and produces strong $\mathrm{Pd}-\mathrm{C}_{6} \mathrm{~F}_{5}$ bonds, increasing a barrier already high for chelating ligands. See: S.-L. Zhang, L. Huang, L-J. Sun, Dalton Trans., 2015, 44, 4613-4622.

[14] a) A. Ariafard, B. F. Yates, J. Organomet. Chem. 2009, 694, 20752084. b) V. P. Ananikov, D. G. Musaev, K. Morokuma, Eur. J. Inorg. Chem. 2007, 34, 5390-5399. 
Entry for the Table of Contents (Please choose one layout)

Layout 1:

\section{COMMUNICATION}

Text for Table of Contents

Wanting to squeeze your crosscoupling product from their $\mathrm{PdR}^{1} \mathrm{R}^{2}$ precursors? You can measure directly the power of your new $L$ ligand to do the job and rank it using complex cis- $\left[\mathrm{Pd}\left(\mathrm{C}_{6} \mathrm{~F}_{5}\right)_{2}(\mathrm{THF})_{2}\right]$ as meter.

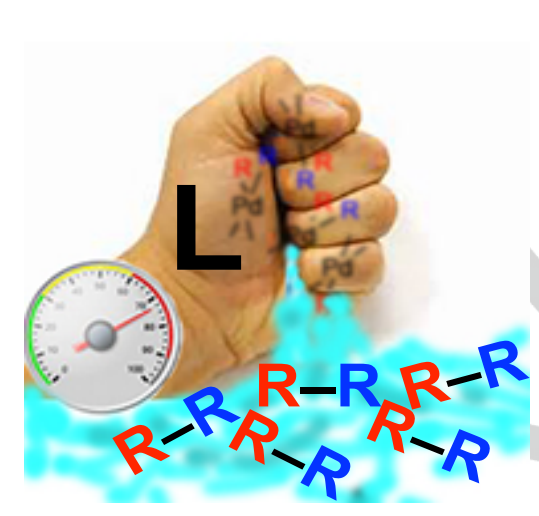

Estefanía Gioria, Juan delPozo, Jesús M. Martínez-llarduya, and Pablo Espinet $^{*}$

Page No. - Page No.

Promoting Difficult C-C Couplings: Which Ligand Does Best?

((Insert TOC Graphic here))

Layout 2:

\section{COMMUNICATION}

((Insert TOC Graphic here))
Author(s), Correspondıng Author(s)*

Page No. - Page No.

Title 